Original article

\title{
Impact of genetic polymorphisms in key enzymes of homocysteine metabolism on the pathophysiology of sickle cell anemia
}

\author{
Danilo Grünig Humberto da Silva, ${ }^{\mathrm{a}, \mathrm{b}, *}$, Edis Belini Junior ${ }^{\mathrm{a}}$, Lidiane de Souza Torres ${ }^{\mathrm{a}}$, \\ Jessika Viviani Okumura ${ }^{a}$, Willian Marcel Barberino ${ }^{a}$, Renan Garcia de Oliveira ${ }^{a}$, \\ Vanessa Urbinatti Teixeira ${ }^{a}$, Clarisse Lopes de Castro Lobo ${ }^{c}$, Eduardo Alves de Almeida ${ }^{\mathrm{b}, \mathrm{d}}$, \\ Claudia Regina Bonini-Domingos ${ }^{\mathrm{a}}$
}

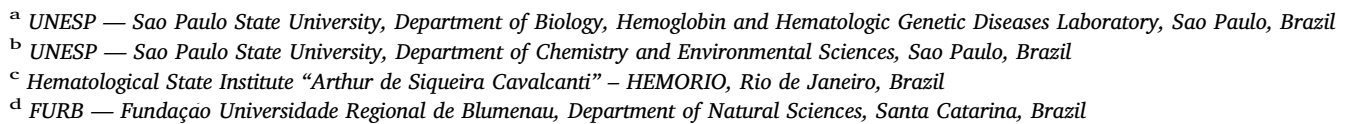

\section{A R T I C L E I N F O}

\section{Keywords:}

Hemoglobin S

Methylenetetrahydrofolate reductase

Cystathionine $\beta$-synthase

Hydroxycarbamide

\begin{abstract}
A B S T R A C T
This work aimed at studying a possible influence of methylenetetrahydrofolate reductase (MTHFR; c. $677 \mathrm{C}>\mathrm{T}$ ) and cystathionine $\beta$-synthase (CBS; 844ins68) polymorphisms on overall oxidative status of sickle cell anemia (SCA) patients and on routine markers, correlating them with hydroxycarbamide (HC) treatment. We evaluated 95 unrelated and diagnosed SCA patients. All patients received a prophylactic treatment with folic acid of $5 \mathrm{mg} /$ day, while 41 (43.2\%) of them were under hydroxycarbamide (HC) treatment (average dose: $22 \mathrm{mg} / \mathrm{kg} / \mathrm{day}$ ). MTHFR and CBS polymorphisms were identified by Polymerase Chain Reaction. Biochemical parameters were measured using spectrophotometric and chromatographic methods. Routine markers were developed by specialized laboratory. We did not find any effect of $677 \mathrm{~T}$ and "I" allele combination on the biomarkers evaluated. On the other hand, MTHFR 677T mutation was related to a depletion of antioxidant capacity, according to the decreased catalase activity and a reduction about $30 \%$ of glutathione levels. Moreover, the presence of the insertion was related to about $23 \%$ less biomolecule oxidation levels and lower monocytes count, but about 14\% higher lactate dehydrogenase activity. These findings may contribute to highlight that the MTHFR and CBS polymorphisms involvement in SCA pathophysiology is likely to be far more complex than it was explored to date.
\end{abstract}

\section{Introduction}

Sickle hemoglobin (HbS) is caused by single point mutation in betaglobin gene (HBB; c.20A > T; rs334), and its homozygosity is termed sickle cell anemia (SCA) which is a chronic and progressively debilitating medical condition common worldwide $[1,2]$. SCA is an hemolytic anemia characterized by a complex pathophysiology that is affected by a number of modifying factors, including co-inheritance of polymorphisms associated to clinical aspects $[3,4]$ and to treatment response [5], as well as a chronic and systemic oxidative stress [6], culminating in an antioxidant deficiency $[7,8]$.

Glutathione (GSH) is a tripeptide, $\gamma$-L-glutamyl-L-cysteinylglycine, present at high concentrations (about $2 \mathrm{mM}$ ) in healthy erythrocytes as the most abundant non-protein thiol that defends against oxidative stress [9]. However, GSH concentration is significantly reduced in SCA patients $[7,10]$, with some studies noting a $50 \%$ decrease in sickle erythrocytes compared with healthy ones [11], even though its de novo synthesis and recycling rate have been shown to be higher as compared to healthy erythrocytes [7]. GSH is synthesized from cysteine, glutamic acid, and glycine in a two ATP-requiring enzymatic steps, being the availability of the first amino acid a rate limiting of GSH synthesis $[9,12]$. Under physiological conditions, cysteine is derived from the diet, protein breakdown and transsulfuration pathway that allows the utilization of methionine for GSH synthesis $[9,13]$.

Transsulfuration pathway plays a significant role in the complex folate-dependent homocysteine (Hcy) metabolism along to the remethylation pathway [14]. Methylenetetrahydrofolate reductase (MTHFR) and cystathionine $\beta$-synthase (CBS) are key enzymes that

\footnotetext{
* Corresponding author at: UNESP — Sao Paulo State University, Department of Biology, Hemoglobin and Hematologic Genetic Diseases Laboratory, Cristovão Colombo Street 2265, Jardim Nazareth, Postal code: 15054-000, São José do Rio Preto, São Paulo, Brazil.

E-mail address: dangrunig@gmail.com (D.G.H. da Silva).
} 
play a role in the balance of Hcy concentrations by converting it to methionine or cystathionine, respectively [15-17]. Genetic defects occur in either genes encoding for MTHFR and CBS enzymes, leading to an alteration of Hcy levels that may be involved in the cysteine availability. Among the polymorphisms described for these enzymes, the most studied ones are single point mutation in MTHFR gene (c. 677C > T; rs1801133) [18] and a 68-bp insertion in the exon 8 coding region of CBS (844ins68) [19].

The MTHFR 677T allele is associated with reduced enzymatic activity, decreased folate concentrations in serum and red blood cells, increased plasma Hcy levels $[18,20]$, and it is a risk factor for vascular complications [21], including in SCA patients [22-24]. Otherwise, there is no consensus about the 68-bp insertion effect on CBS activity and on Hcy levels [19,25,26]. In spite that, Alves-Jacob [23] showed that the presence of the 844ins68 mutation in the CBS gene is a risk factor for vaso-occlusive episodes in SCA patients. Furthermore, recent studies have demonstrated that defects in either transsulfuration or remethylation pathways are related to increased generation of reactive oxygen species (ROS) [27-29] that could exacerbate the oxidative condition in SCA patients.

Some studies have been carried out to determine the association of the MTHFR (677C > T) or CBS (844ins68) polymorphisms with higher risk to develop vascular complications in SCA patients. However, there is no report regarding the functional impacts of these polymorphisms on GSH concentration and consequently on oxidative stress and routine markers in SCA patients. For this reason, this work aimed at studying a possible influence of the mentioned polymorphisms on overall oxidative status of SCA patients and on routine markers, correlating them with hydroxycarbamide (HC) treatment.

\section{Subjects and methods}

\subsection{Subjects}

We evaluated 95 unrelated Brazilian SCA patients regardless gender (mean age: 24.4 years old; range: $10-59$ years old). All subjects were regularly in clinical follow-up in the Blood Center of Rio de Janeiro (RJ, Brazil) and had access to the same medication protocol established and regulated by the Brazilian Ministry of Health for the entire national territory. The Data Safety Monitoring Board (DSMB), according to Brazilian Regulations, approved the study.

After they gave their informed consent, all patients have answered a questionnaire in order to screen them according to the following exclusion criteria. Patients were asked specifically whether they were taking any nutritional supplements, nonsteroidal anti-inflammatory drugs (NSAID), opioids, or iron chelating agents, e.g. Further exclusion criteria were pregnant women, smokers or drinkers and patients who had a stroke, pain and/or hemolytic crisis, or received blood transfusion within the 120 days prior to the study start. The medications used were accessed and those ones taking medication known to affect the analyzed parameters (such as acetylsalicylic acid, antibiotics or vitamins) within $24 \mathrm{~h}$ of sample collection were excluded.

The Blood Center of Rio de Janeiro developed the analysis of all patient routine marker, such as complete blood count, hemolytic, hepatic and renal markers. These data were obtained by reviewing the medical records from the Blood Center database, where the information given in questionnaires were also confirmed for each patient, under supervision of clinicians responsible for the patients. Finally, we characterized the baseline outcomes from the patients, regarding demographic data, specific medication use, beta-globin haplotype profile, and the routine markers (Table 1).

\subsection{Biological samples}

Blood samples (about $8 \mathrm{~mL}$ ) were collected through venipuncture in ethylenediaminetetraacetic acid (EDTA) tubes. Four milliliters (mL) of
Table 1

Characterization of study group.

\begin{tabular}{|c|c|c|}
\hline Markers & $\begin{array}{l}\text { SAMPLE GROUP } \\
(N=95)\end{array}$ & REFERENCE VALUES \\
\hline Age [yr: $\bar{X}(95 \% \mathrm{CI})$ & $24.3(21.5-27.2)$ & - \\
\hline Gender $[N(\%)]$ & & - \\
\hline Female & $53(55.8)$ & \\
\hline Male & $42(44.2)$ & \\
\hline Medication use $^{\mathrm{a}}[N(\%)]$ & & - \\
\hline $\begin{array}{l}\mathrm{HC}^{+} \text {(average dose: } 22 \mathrm{mg} \text { / } \\
\mathrm{kg} / \text { day) }\end{array}$ & $41(43.2)$ & \\
\hline $\mathrm{HC}^{-}$ & $54(56.8)$ & \\
\hline $\begin{array}{l}\text { Beta globin haplotype profile } \\
\text { [N(\%)] }\end{array}$ & & - \\
\hline Bantu/Bantu & $42(44.2)$ & \\
\hline Bantu/Benin & $19(20.0)$ & \\
\hline Bantu/Cameroon & $1(1.1)$ & \\
\hline Bantu/Atypical & $8(8.4)$ & \\
\hline Benin/Benin & $6(6.3)$ & \\
\hline Benin/Cameroon & $1(1.1)$ & \\
\hline Benin/Atypical & $2(2.1)$ & \\
\hline Atypical/Atypical & $16(16.8)$ & \\
\hline \multicolumn{3}{|l|}{ Routine markers $[\bar{X}(95 \% \mathrm{CI})]$} \\
\hline Erythrocytes $(\mathrm{k} / \mu \mathrm{L})$ & $2.49(2.39-2.60)$ & $4.5-6.0$ \\
\hline HbF levels (\%) & $9.6(8.1-11.1)$ & $0.0-1.0$ \\
\hline Hemoglobin (g/dL) & $8.3(8.0-8.5)$ & $11.5-17.0$ \\
\hline Hematocrit $(\%)$ & $23.4(22.6-24.2$ & $35.0-43.0$ \\
\hline $\operatorname{MCV}(\mathrm{FL})$ & $93.0(90.4-95.5)$ & $77.0-100.0$ \\
\hline $\mathrm{MCH}(\mathrm{PG})$ & $33.0(32.0-34.0)$ & $25.0-34.0$ \\
\hline MCHC (G/DL) & $35.0(34.3-35.6)$ & $31.0-37.0$ \\
\hline Leucocytes $(\mathrm{k} / \mu \mathrm{L})$ & $9.6(9.0-10.1)$ & $5.0-13.0$ \\
\hline Neutrophils $(\mathrm{k} / \mu \mathrm{L})$ & $4.4(4.0-4.8)$ & $1.5-10.0$ \\
\hline Lymphocytes $(\mathrm{k} / \mu \mathrm{L})$ & $3.8(3.5-4.0)$ & $1.0-6.0$ \\
\hline Monocytes $(\mathrm{k} / \mu \mathrm{L})$ & $0.66(0.60-0.72)$ & $0.08-1.3$ \\
\hline Eosinophils $(\mathrm{k} / \mu \mathrm{L})$ & $0.43(0.32-0.53)$ & $0.0-0.60$ \\
\hline Basophils $(\mathrm{k} / \mu \mathrm{L})$ & $0.15(0.13-0.16)$ & $0.0-0.20$ \\
\hline Platelets $(\mathrm{k} / \mu \mathrm{L})$ & $434.4(406.77-462.1)$ & $140.0-400.0$ \\
\hline Reticulocytes (\%) & $9.9(9.03-10.7)$ & $0.80-2.0$ \\
\hline Reticulocytes $(\mathrm{k} / \mu \mathrm{L})$ & $240.6(222.2-259.1)$ & $60.0-150.0$ \\
\hline LDH (U/L) & $1142.8(891.2-1394.5)$ & $<480.0$ \\
\hline AST (U/L) & $53.7(49.5-57.9)$ & $<35.0$ \\
\hline ALT (U/L) & $25.3(21.2-29.4)$ & $<41.0$ \\
\hline TB (mg/dL) & $3.3(2.9-3.7)$ & $<1.0$ \\
\hline $\mathrm{DB}(\mathrm{mg} / \mathrm{dL})$ & $0.60(0.54-0.66)$ & $<0.20$ \\
\hline IB (mg/dL) & $2.7(2.3-3.1)$ & $<0.80$ \\
\hline ALP (U/L) & $145.0(125.1-164.9)$ & $53.0-141.0$ \\
\hline GGT (U/L) & $61.0(44.9-77.0)$ & $8.0-73.0$ \\
\hline Creatinine (mg/dL) & $0.73(0.67-0.79)$ & $0.60-1.30$ \\
\hline
\end{tabular}

Hb F: fetal hemoglobin; MCV: Mean corpuscular volume; MCH: Mean corpuscular hemoglobin; MCHC: Mean cell hemoglobin concentration; LDH: lactate dehydrogenase; AST: aspartate transaminase; ALT: alanine transaminase; TB: total bilirubin; DB: direct bilirubin; IB: indirect bilirubin; AF: alkaline phosphatase; GGT: gamma-glutamyl transferase

${ }^{a}$ All the patients studied received a prophylactic treatment with folic acid of $5 \mathrm{mg} /$ day since the SCA diagnosis

whole blood were used for cytological, electrophoretic and chromatographic hemoglobin identification tests, as well as for DNA extraction from leucocytes for further molecular analysis. The other $4 \mathrm{~mL}$ were firstly used to prepare hemolysate for CAT activity analysis - whole blood diluted in ultrapure water $(1: 50, \mathrm{v} / \mathrm{v})$. Then the blood samples were centrifuged in a refrigerated centrifuge at $800 \mathrm{~g}$ for $15 \mathrm{~min}$ at $4{ }^{\circ} \mathrm{C}$ in order to obtain plasma for lipid peroxidation assay while buffy coat were carefully removed. The erythrocytes obtained were washed three times with cold phosphate-buffered saline (PBS $-136 \mathrm{mM} \mathrm{NaCl}, 3 \mathrm{mM}$ $\mathrm{KCl}, 10 \mathrm{mM} \mathrm{Na}_{2} \mathrm{HPO}_{4} / \mathrm{KH}_{2} \mathrm{PO}_{4}, \mathrm{pH}$ 7.4). The supernatant and buffy coat were carefully removed after each wash. Finally, the erythrocytes were diluted in a $3.5 \mu \mathrm{M}$ 2-mercaptoethanol $10 \mu \mathrm{M}$ NADP $2.7 \mathrm{mM}$ EDTA hemolyzing solution (1:20, v/v) for GST, GPx and GR activities and GSH content measurement. All hemolysates and plasma samples were immediately frozen at $-80{ }^{\circ} \mathrm{C}$ until the analysis. 


\subsection{Hemoglobin identification tests}

Cell morphology microscopic analysis was performed on the stained blood using May-Grünwald-Giemsa at photonic microscopy using $40 \times$ objective. Hb phenotype identification was performed using electrophoresis on cellulose acetate $\mathrm{pH} 8.6$ [30], and agar electrophoresis at $\mathrm{pH} 6.2$ [31]. The Hb fraction quantification was obtained using high performance liquid chromatography (HPLC) by the automated VARIANT $^{\mathrm{TM}}$ equipment (Bio-Rad Laboratories, Hercules, CA, USA), according to manufacturer's manual.

\subsection{Molecular analysis}

DNA was extracted from peripheral blood leucocytes and isolated by phenol-chloroform methodology [32]. $H B B * S$ homozygous genotype was confirmed by molecular analysis by PCR-RFLP using DdeI as restriction endonuclease (New England BioLabs, Ipswich, MA, USA) [33]. Beta globin haplotypes were determined through the PCR-RFLP analysis of the following polymorphic restriction sites: $\gamma \mathrm{G}$ (Hind III), $\gamma \mathrm{A}$ (Hind III), $\psi \beta$ (Hinc II), $3^{\prime} \psi \beta$ (Hinc II) and $5^{\prime} \beta$ (Hinf I), as previously described [34]. MTHFR (c.677C $>$ T) polymorphism was assessed through PCR-RFLP using FastDigest HinfI (Thermo Fisher Scientific Inc., Waltham, MA, USA) as restriction endonuclease, according to Frosst et al. [18]. Briefly, the PCR product (198-bp) remained uncleaved for ancestral allele, whereas mutant one produced 175- and 23bp fragments. CBS (844ins68) mutation was detected using PCR as previously described by Tsai et al. [25]. After PCR, we obtained a 184bp fragment for ancestral allele and a 252-bp for mutant one.

\subsection{Biochemical measurements}

As an oxidation marker, we measured colored adducts produced by the reaction with thiobarbituric acid in the plasma samples [35], according to Silva et al. [36]. The products were detected by high performance liquid chromatography coupled to UV/Vis detector (UV/ Vis-HPLC) $[37,38]$. The HPLC system consisted of ESA584 pump and an ESA526 UV/Vis detector set in $532 \mathrm{~nm}$. The derivative extracts were separated by a Shimadzu (Kyoto, japan) C18 column $(150 \times 4.6 \mathrm{~mm}$, $5 \mu \mathrm{m}$ ) that was fitted with a guard column cartridge of the same composition. The mobile phase (potassium phosphate $0.05 \mathrm{M}, \mathrm{pH} 7.0$, with $40 \%$ methanol) was pumped at an isocratic flow of $1 \mathrm{~mL}$ min-1. Chromatogram monitoring and peak identification and quantification were performed using the EZ Chrom Elite software (Agilent Technologies, Santa Clara, CA, USA). The calculations were based on a calibration curve previously constructed and prepared according to same procedure used for the samples from authentic standards. The results were expressed in $\mathrm{ng} / \mathrm{mL}$.

As antioxidant markers, catalase (CAT) [39], glutathione $S$-transferase (GST) [40], glutathione peroxidase (GPx) [41], and glutathione reductase (GR) [42], activities were determined spectrophotometrically, while GSH concentration was determined HPLC coupled to a coulometric electrochemical detection (ECD-HPLC) [43]. We filtered the hemolysate aliquot through Millex syringe filter units $(0.22 \mu \mathrm{m})$ and we directly injected into the HPLC system. The system consisted of ESA584 pump, a model 5021 conditioning cell that was maintained at a potential of $+900 \mathrm{mV}$ and a dual cell model 5011 analytically with potential set at $250 \mathrm{mV}$ (first cell) and $650 \mathrm{mV}$ (second cell) (ESA Coulochem III, Bedford, MA, USA). The column was an ACE C18 $(250 \times 4.6 \mathrm{~mm}, 5 \mu \mathrm{m})$ also fitted with a guard column cartridge of the same composition. The mobile phase consisted of sodium phosphate $0.05 \mathrm{M}$, octanesulfonic acid $0.025 \mathrm{M}, \mathrm{pH} 2.5$, with acetonitrile (2\%; v/ v) was pumped at an isocratic flow of $0.9 \mathrm{~mL}$ min-1.

Chromatogram monitoring and peak identification and quantification were performed using the same software used in the oxidation marker assay. The calculations were based on a calibration curve previously constructed by injecting authentic GSH standards into the
HPLC system. The antioxidant enzymes were expressed in $\mathrm{U} / \mathrm{mL}$, while GSH levels were in $\mu \mathrm{M}$.

\subsection{Statistical analysis}

Statistical analysis were performed in groups with at least three individuals using the Statistica 8.0 software (StatSoft Inc., Tulsa, OK, USA), while the graphics were done using GraphPad Prisma version 5.01 for Windows (GraphPad Software, La Jolla, CA, USA).

We assessed data normality by using Normal Probability Plots of Residuals. Thus, some data were either logarithmically transformed $\left(\log _{10}\right)$ or identified as outliers and removed from comparison analysis. We also tested data homoscedasticity by Levene's test, assuming a significance level of 0.05 . For comparison analysis, we used General Linear Models (GLM), because these approaches generalize to unbalanced designs and designs with more factors, including crossed and nested, and combinations of categorical and continuous variables $[44,45]$. Thus, allowing checking HC usage outcome, individual mutation effects, as well as any interaction effects. That way we have established the MTHFR and CBS genotypic distributions and HC usage as predictors with adjustment for gender, and age at investigation and the biochemical parameters evaluated as dependent variables. If appropriate, we applied the Tukey-Kramer post hoc test, a simple and reliable multiple comparison for unequal sample sizes [44].

In order to assess association degree between biochemical parameters and HbF levels, we used Pearson's correlation. Data were expressed as mean $\pm 95 \%$ confidence intervals of their biological values and we considered $\mathrm{p}<0.05$ as statistically significant $[44,45]$.

\section{Results}

Among the 95 SCA patients evaluated, we found 66 (69.5\%) wild homozygous for MTHFR (677CC), 27 (28.4\%) heterozygous (677CT) and two $(2.1 \%)$ mutant homozygous (677TT), leading to an allelic frequency of 0.84 for the ancestral allele (677C) and 0.16 for the mutant one (677T). The allelic frequency obtained for CBS (844ins68) mutation was very similar to the MTHFR one: 0.85 for the ancestral allele (A) and 0.15 for the insertion (I). Moreover, we identified the following genotyping distribution for $C B S$ gene $-69(72.6 \%)$ ancestral homozygous (AA), $23(24.2 \%)$ heterozygous (AI) and three (3.2\%) insertion homozygous (II). In addition, the co-heritance prevalence of both mutation in at least one chromosome (T_/__ was $8.4 \%$.

In order to address the proportion of generalized variance of SCA pathophysiology that is accounted by MTHFR 677T polymorphism and CBS 844ins68 insertion, we evaluated 31 biochemical parameters (25 clinical follow-up parameters and 6 oxidative stress markers), in people with SCA treated or not with HC. Unexpectedly, according to the statistical analysis adopted, we did not find any protective effect of HC treatment on oxidation marker and antioxidants evaluated. On the other hand, people with SCA under HC use presented almost twice the $\mathrm{HbF}$ values than those patients not treated (Fig. 1a), leading to improvement of MCV (Fig. 1b) and MCH (Fig. 1c), since HbF levels correlated positively with these two erythrocyte indices (Fig. 1d).

Still with regard to HC use, we found other well-documented pharmacological effects such as average reduction about $20 \%$ of leukocyte count (Fig. 2), as well as an improvement of hemolytic markers (Fig. 3). We did not observe any other influence of HC treatment on the remaining parameters evaluated.

Regarding the influences of the mutations investigated, we adopted a dominant genetic model. For MTHFR (677C > T), we compared wild homozygous (CC) against the rare homozygous variant combined with the heterozygous ( $\mathrm{T}_{-}$), while for CBS (844ins68) the comparison was between ancestral homozygous (AA) against the association of heterozygous and insertion homozygous (I_). Furthermore, we performed for each gene individually interaction with $\mathrm{HC}$ treatment. In this regard, we did find none gene-HC treatment interaction, thus, confirming that 

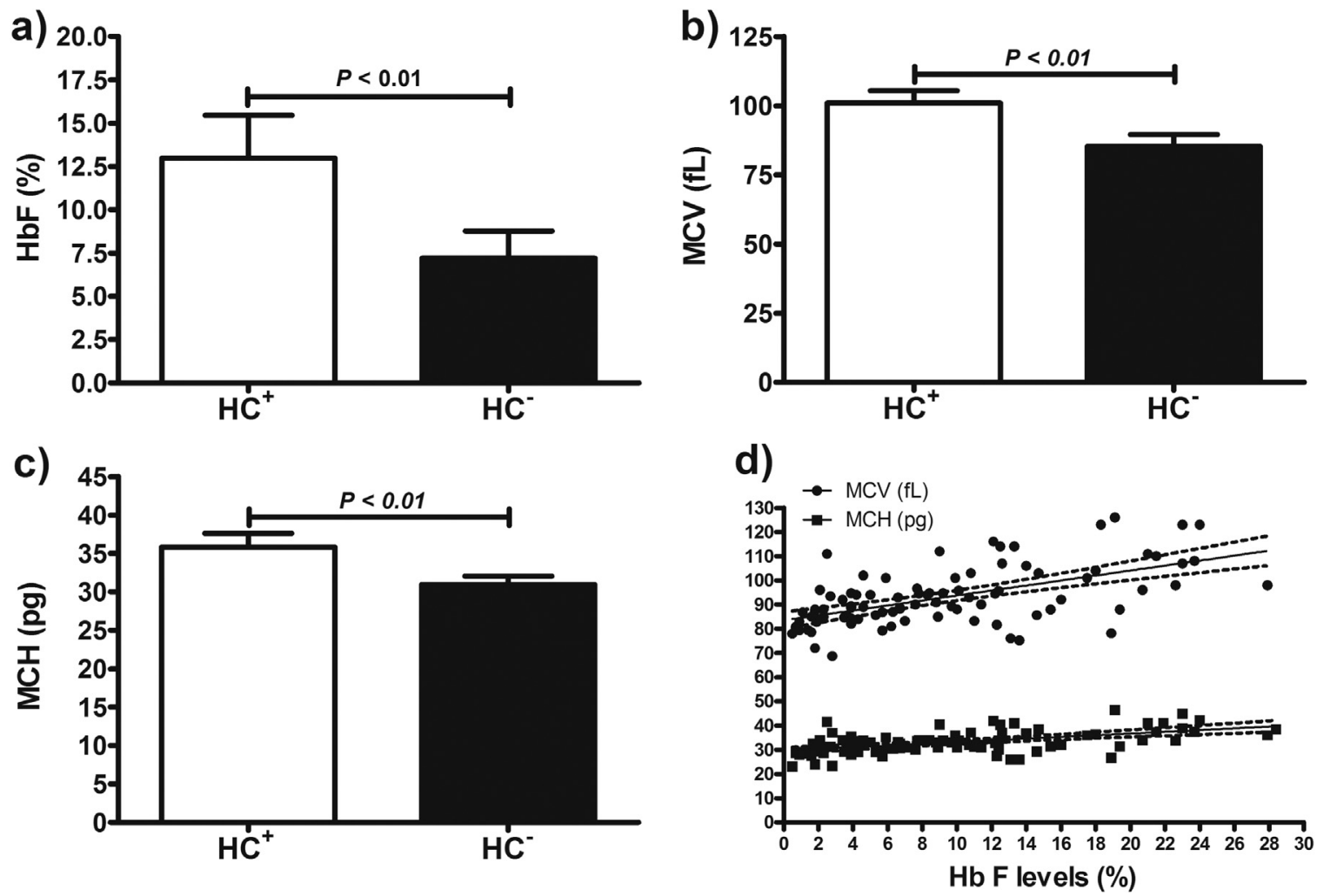

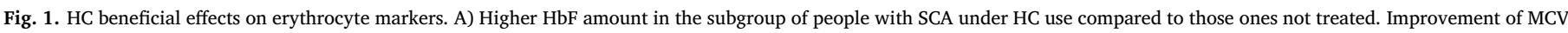

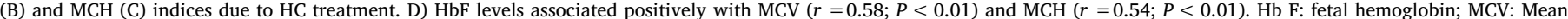

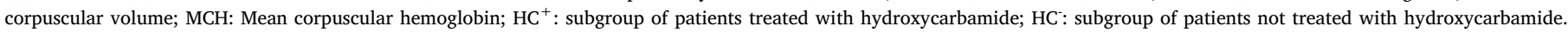

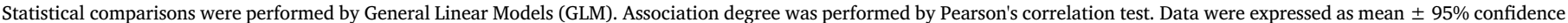
intervals.
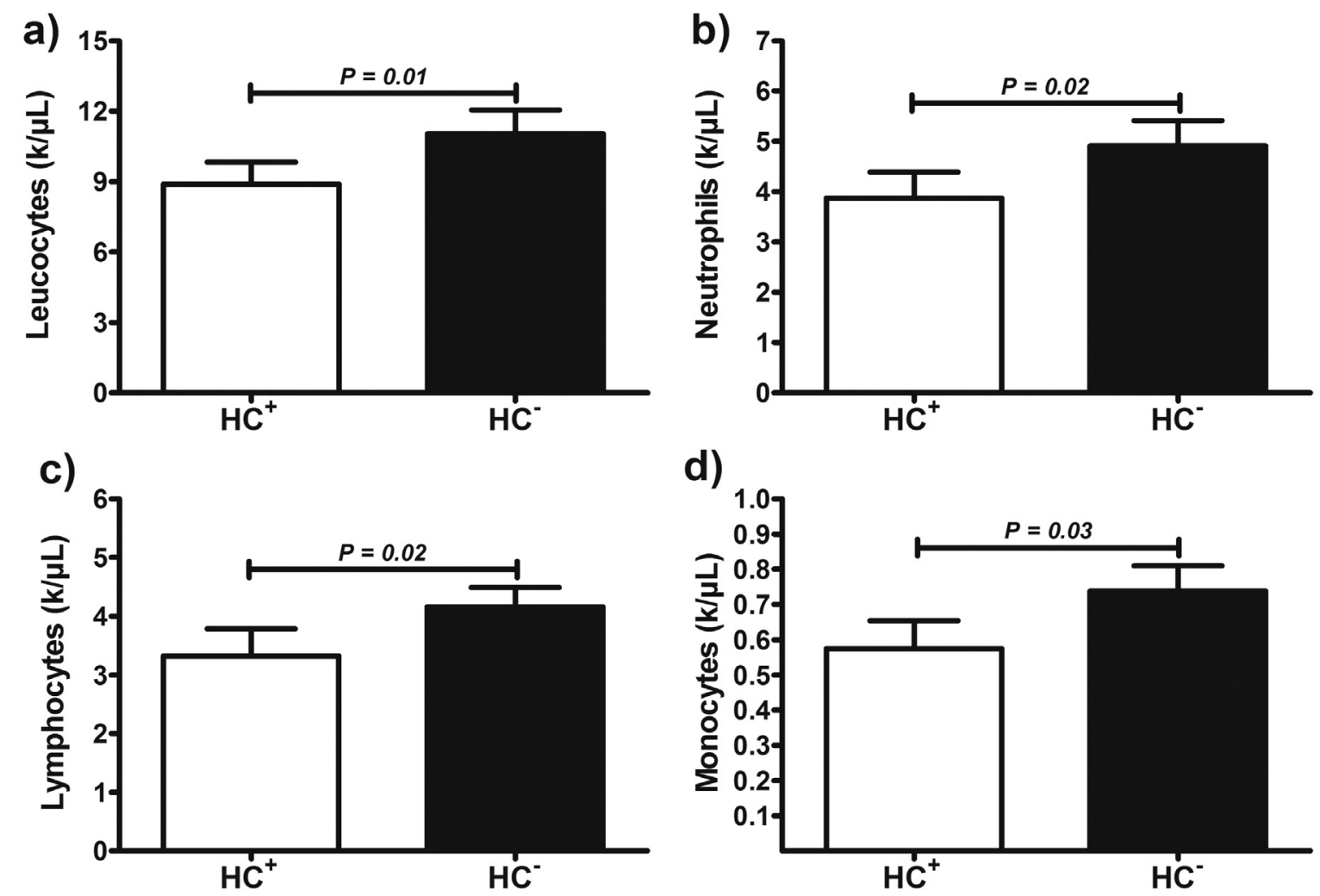

d)

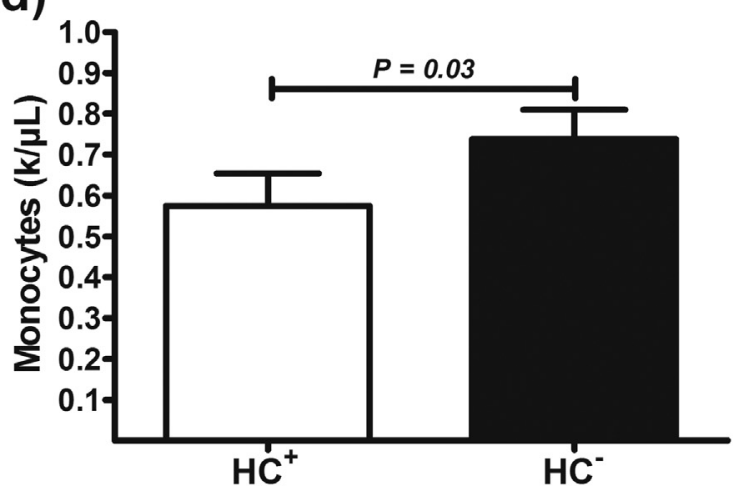

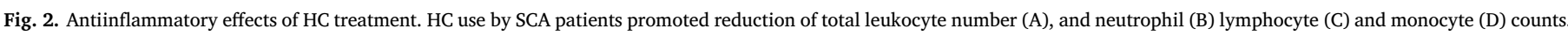

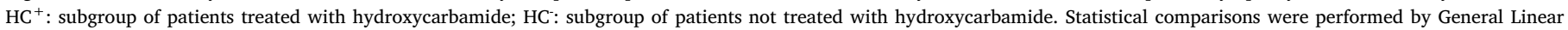
Models (GLM). Data were expressed as mean $\pm 95 \%$ confidence intervals. 

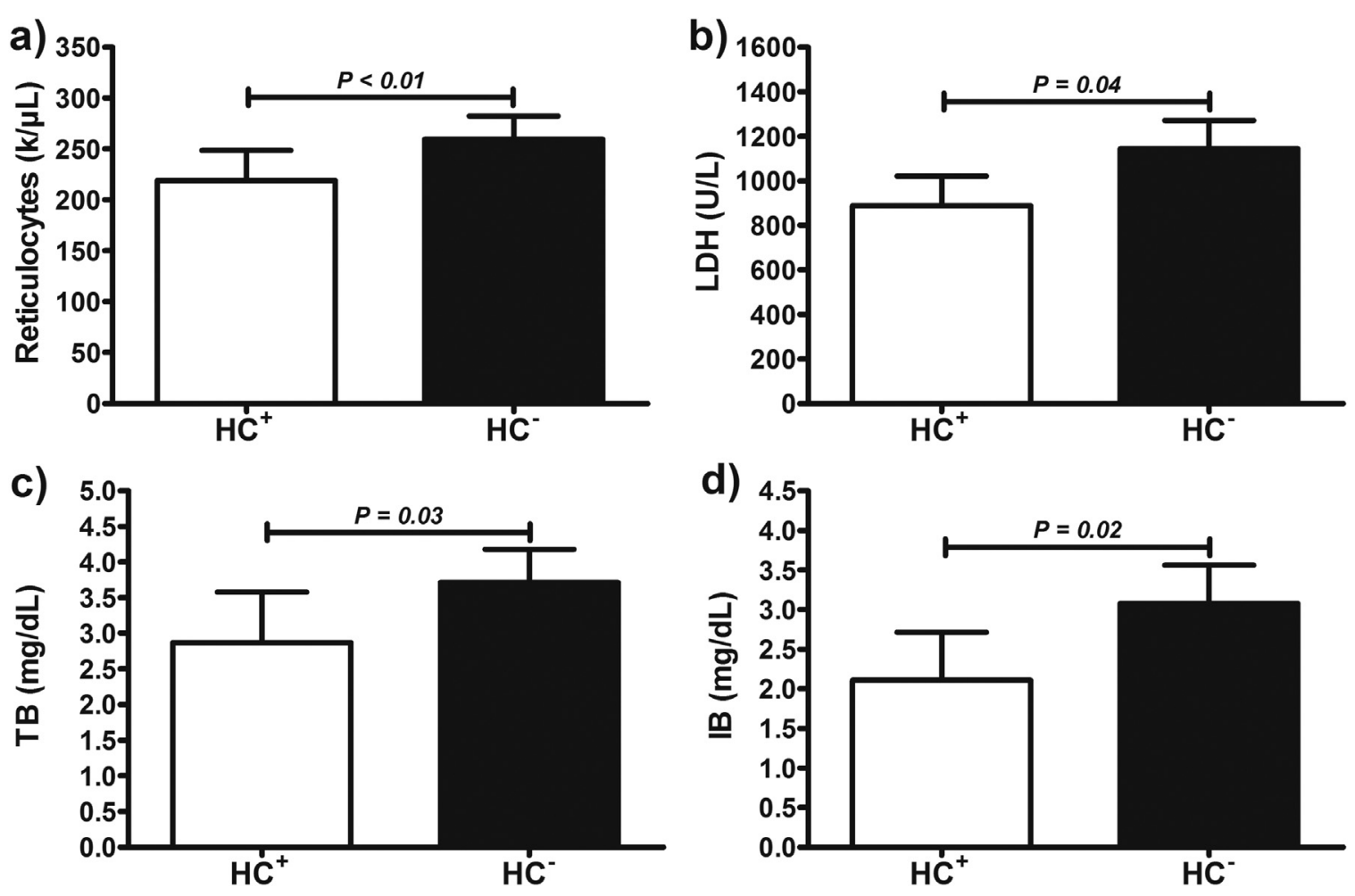

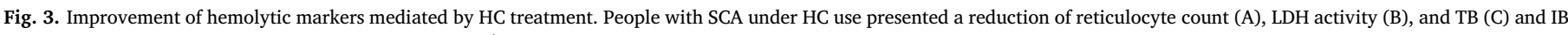

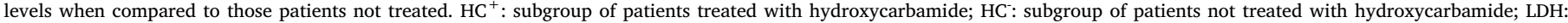

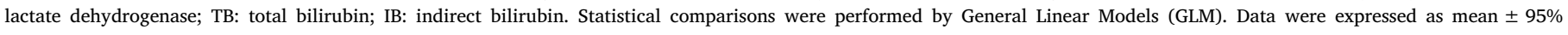
confidence intervals.

HC influence on patient hematological and hemolytic profile, regardless the presence of the mutations studied.

We also assessed a possible gene-gene interaction effect on HC response and on biomarkers evaluated. In this way, the statistical comparisons were performed through a combined dominant model: ancestral homozygous for both MTHFR (677C > T) and CBS (844ins68) polymorphisms (CC/AA) against those patients at least heterozygous for both genetic variants studied (T_/__). Unexpectedly, we did not find any additive, synergic or even antagonistic effect of $677 \mathrm{~T}$ and "I" alleles on the biomarkers evaluated.

Notwithstanding, we found only individually gene effects. The presence of the $677 \mathrm{~T}$ allele in at least one chromosome was related to a depletion of antioxidant capacity, according to the decreased CAT activity (Fig. 4a) and a reduction about $30 \%$ of GSH levels (Fig. 4b) in the $T_{-}$subgroup when compared to the CC counterpart. In spite of this, we did not find any statistical difference in biomolecule oxidation levels, as well as in the other antioxidant evaluated. The co-inheritance of $H B B * S$ and MTHFR $677 \mathrm{~T}$ did not influence any of the routine markers assessed.

Remarkably, the co-inheritance of $H B B * S$ and $C B S$ (844ins68) influenced the biomarkers analyzed in an entirely different and dual way. On the one hand, people with SCA and at least heterozygous for CBS (844ins68) showed about 23\% less oxidation product levels (Fig. 5a) and lower monocytes count (Fig. 5b) than those patients without the insertion. These effects might be considered beneficial or protective ones. On the other hand, the I_ subgroup presented about $14 \%$ higher LDH activity when compared to the AA one (Fig. 5c), which might be interpreted negatively for people with SCA. The other antioxidant and routine markers analyzed did not differ statistically between the $C B S$ subgroups.

\section{Discussion}

Although SCA is one of the first disorders to be clearly defined at molecular level, genetic understanding of the basis for disease expression variability is still unclear [46]. In this way, despite $\mathrm{HbS}$ presence is indispensable for the disease establishment, several other phenomena affected by a multitude of genes other than the one directly involved $\left(H B B^{*} S\right)$ play an important role [47]. Thus, to our knowledge, this is the first report focusing on the possible influence of the polymorphisms in MTHFR and CBS genes and their association on oxidative stress markers and routine measurements, and on HC treatment in SCA patients.

The prevalence of MTHFR (677C > T) and CBS (844ins68) mutations reveals an extensive ethnic and geographic variability $[48,49]$. For instance, the prevalence of MTHFR homozygosity (677TT) may vary between $1 \%$ and $30 \%$ in the general population [50], while $C B S$ homozygosity shows a much lower variance, ranging from absent to $4 \%$ [48]. However, the genotypic frequency data obtained for these polymorphisms in our study agrees to previous studies in Brazilian SCA patients [22,23,51].

$\mathrm{HC}$ administration is the only currently available disease-modifying therapy for SCA [52-54]. HC is an antineoplastic drug, which its main pharmacological action is to increase $\mathrm{HbF}$ levels [52]. It has other potentially beneficial effects including improved nitric oxide (NO) metabolism, reduced red cell-endothelial interaction, decreased erythrocyte density [52], improvement of MCV and MCH [55,56], and reduction of white cell counts [57], lipid peroxidation levels [58,59] and hemolysis [60]. We observed these expected pharmacological effects, regardless the presence of both polymorphisms investigated. Despite patients' response to HC variation be attributed to several single nucleotide polymorphisms (SNPs) in various genes that are linked or not to the $\beta$-globin gene cluster [61], we did not observe any HC differential response promoted by the polymorphisms evaluated but both mutations have individually influenced one or other biomarker assessed.

The SNP at position 677 in the MTHFR gene had the functional influence on $30 \%$ and $65 \%$ reduced enzyme activity in heterozygous (CT) and homozygous (TT) variants, respectively [62]. This loss of 

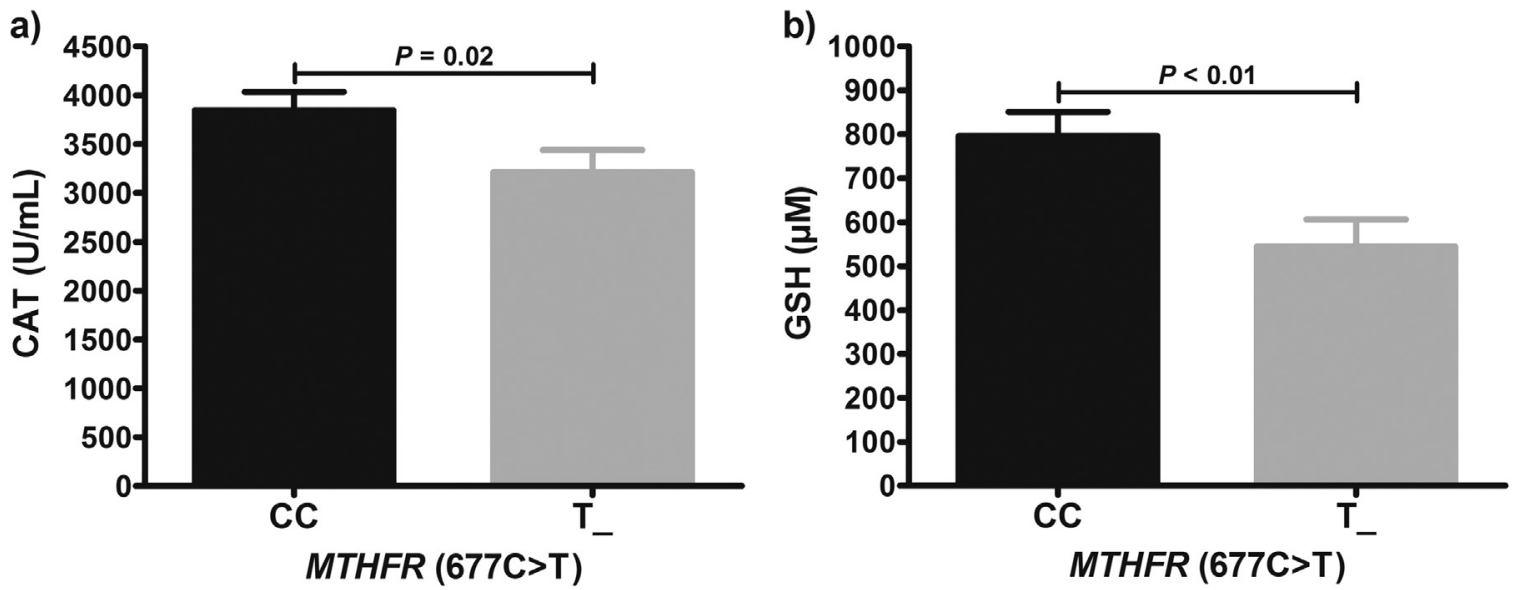

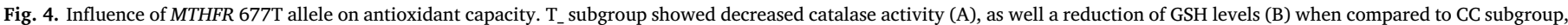

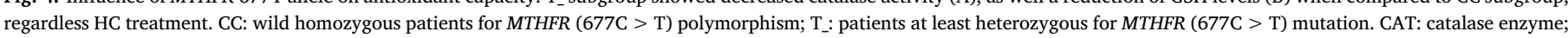

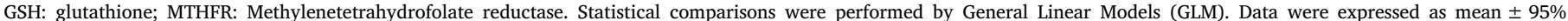
confidence intervals.

activity promotes a significantly reduction in the production of 5Methyl tetrahydrofolate (5-MTHF, the primary form of plasma folate), culminating in lower plasma and erythrocyte folate concentrations [63]. In addition, SCA patients normally present lower serum cobalamin (Vitamin B12) levels, without macrocytosis or hypersegmented neutrophils [64-66]. Deficiency in any one of these micronutrient can cause increased erythroid progenitor cell death through impaired DNA synthesis and its consequences during erythropoiesis [67]. Moreover, according to Moestrup [68], during increased hemolysis (one charac-
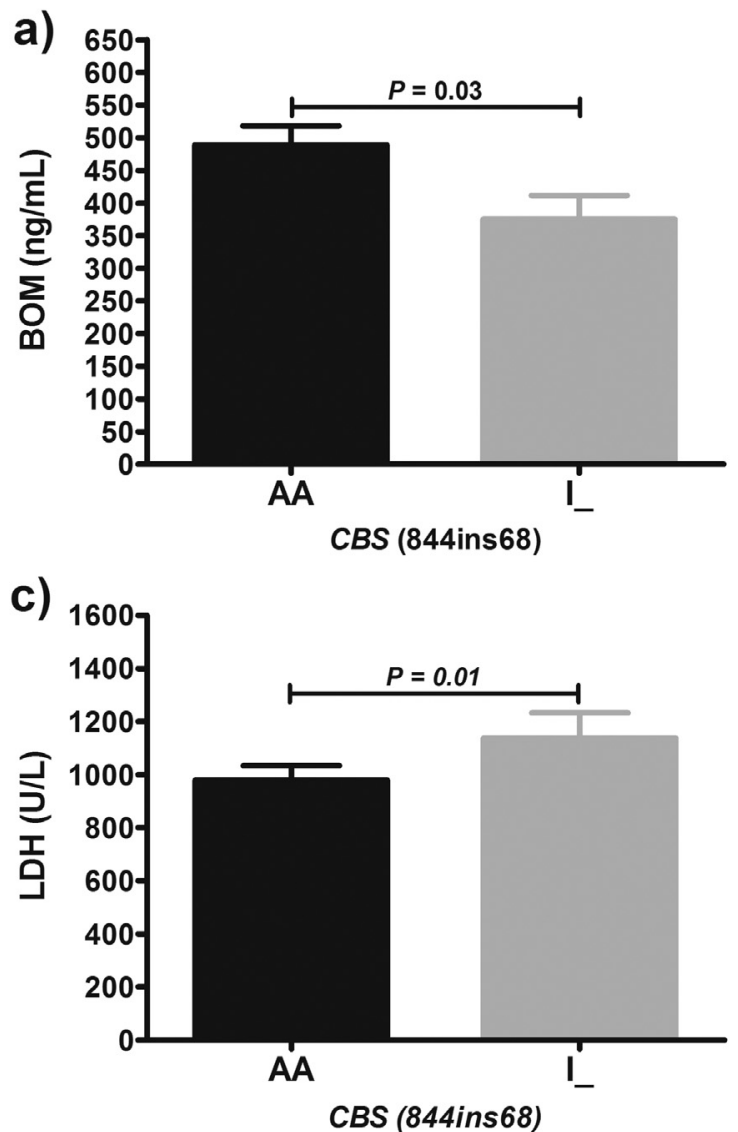

teristic pathophysiological event of SCA), erythropoiesis is accelerated by erythropoietin (EPO), making this process extremely sensitive to deficiency of cobalamin and folate. In this way, we expected that the coinheritance of $H B B * S$ and MTHFR 677T would worsen clinical outcome of SCA patients. However, MTHFR polymorphism did not significantly affect any of routine markers.

Further, 5-MTHF is found to be an effective scavenger of superoxide [69]. Thus, long-term depletion of folate/methyl is shown to decrease reduced/oxidized GSH ratio, alter activity of manganese-dependent

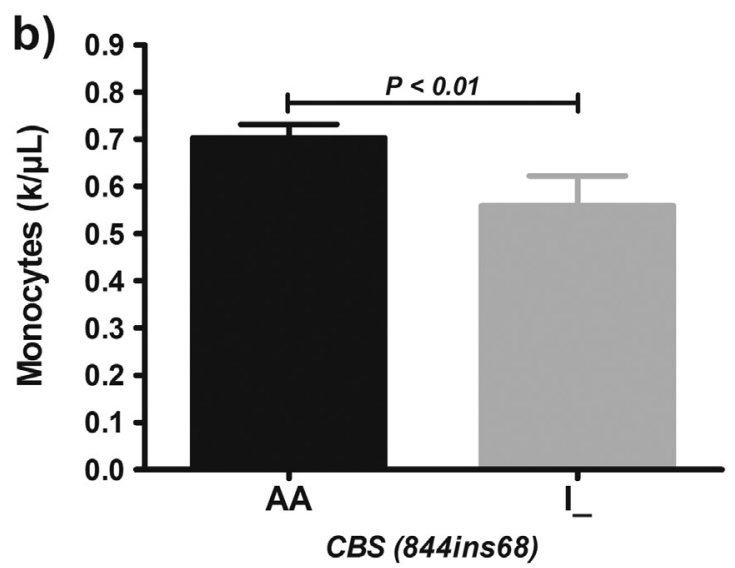

d)

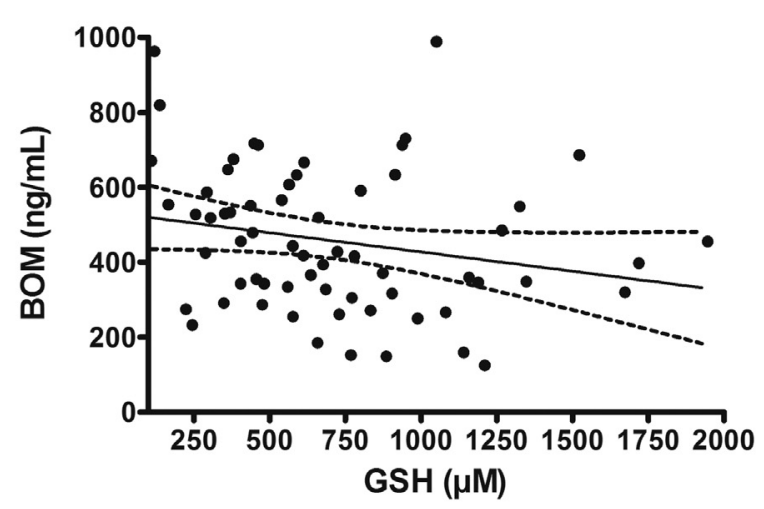

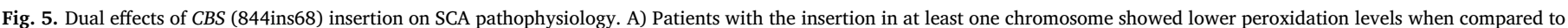

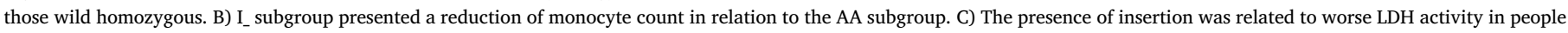

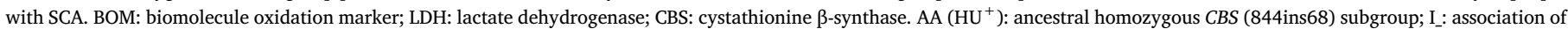

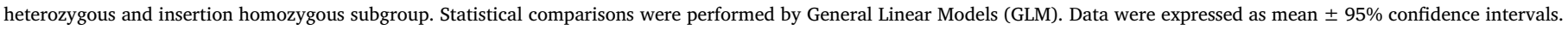


superoxide dismutase (Mn-SOD), CAT and GPx and induce irreparable oxidative DNA damage [70]. Our data corroborated these features, according to the decreased antioxidant capacity in the $\mathrm{T}_{-}$subgroup. Furthermore, MTHFR reduced activity caused by the polymorphism studied is associated with elevated Hcy levels [71,72], which in turn are responsible for an increased ROS production in several tissues such as bone and vascular endothelium $[73,74]$, and positively correlated with MDA levels [75]. However, this last association was not observed in our study. We believe that the lack of increasing oxidation product levels can be attributed to daily folic acid treatment administered in the SCA patients evaluated. According to Dragani et al. [27], a regimen of folate intake ( $5 \mathrm{mg}$ daily) is capable to produce a $58 \%$ decrease in Hcy levels, improving vascular function and oxidative stress in patients with coronary heart disease. Although SCA patients routinely using folic acid to improve erythropoiesis, this supplementation did not seem to be able of avoid or mitigate antioxidant consumption in SCA patients at least heterozygous for MTHFR $(677 \mathrm{C}>\mathrm{T})$, which can cause other consequences than rise in oxidation biomolecule amount.

For the insertion (844ins68) in the CBS gene, it was initially thought to mandate the use of an insertion-associated premature stop codon in the CBS mRNA and result in the translation of an inactive truncated enzyme [19]. Subsequently, Tsai et al. [25] showed that the 68-bp insertion generates an alternative splice site that permits the elimination of the entire inserted region, thereby allowing the formation of a normal mRNA transcript and a fully functional CBS enzyme. Moreover, it was speculated that this insertion is associated with somewhat higher CBS enzyme activity [26]. Assuming that the CBS (844ins68) mutation causes higher CBS activity, and taking into consideration the fact that the transsulfuration pathway is activated in order to combat oxidative stress and GSH depletion [76], these features justify the lower oxidation marker levels found in SCA patients with the insertion in at least one chromosome.

Other fact that might have contributed to the biomolecule oxidation results obtained is the basic function of CBS, promoting the condensation of Hcy with serine to form cystathionine [14]. Thus, the activation of CBS along with the plausible higher CBS activity promoted by insertion (844ins68) in the CBS gene may have decreased the Hcy levels, consequently ROS production and oxidation adducts. This reduction mechanism of Hcy levels hypothesized may also explain our results of monocytes count, since Zhang et al. [77] reported that Hcy is capable of increasing monocyte population in peripheral blood, spleen, and bone marrow in transgenic CBS-deficient mice. Heretofore, one might speculate that $H B B * S$ and $C B S$ (844ins68) co-inheritance had a positive prognosis, but the deviation to transsulfuration pathway in order to replenish GSH concentration may result in decreased $\mathrm{H}_{2} \mathrm{~S}$ level that induces vasoconstriction [76], worsening other characteristic pathophysiological event of SCA, vaso-occlusive events (VOE).

VOE are associated with ischemia/reperfusion damage to tissues that lead to pain and acute or chronic injury affecting any organ system, thus being an important cause of end-organ damage $[78,79]$. Moreover, it is estimated that $10-39 \%$ of VOE occurs with hepatic involvement [80]. This observation along to the facts that transsulfuration pathway is particularly active in hepatocytes [13]; and LDH is also an hepatic enzymes $[79,81]$; should be involved in the worst LDH outcome we found in the I_ subgroup. Thus, we hypothesized that this reflection might be a signal of initial establishment of hepatic dysfunction in the SCA patients from the I_ subgroup. Furthermore, Vitvitsky et al. have addressed a metabolic conundrum by establishing that red blood cells clear sulfide via methemoglobin-catalyzed oxidation of $\mathrm{H}_{2} \mathrm{~S}$ to thiosulfate and polysulfides, suggesting a detrimental mechanism for SCA patients with the insertion studied, since HbS instability contributes to an accelerated autoxidation and higher methemoglobin levels [82]. In this way, the $H B B * S$ and $C B S$ (844ins68) co-inheritance may enhance $\mathrm{H}_{2} \mathrm{~S}$ scavenging, favoring VOE occurrence and its pathophysiological consequences.

Finally, we did not observe any interaction effect of 677T and "I" alleles on the biochemical parameters evaluated, notwithstanding tight relation between cellular one-carbon and GSH metabolism [83-85]. Anyway, considering that one-carbon metabolism is a metabolic pathway that provides a variety of metabolic intermediates, which react either with pro-oxidants or promote antioxidant defense, along with the crucial physiological importance of a tight regulation of Hcy and $\mathrm{H}_{2} \mathrm{~S}$ metabolism in persons with SCA, our results leave new perspectives for further studies to address better the above-mentioned hypotheses.

\section{Conclusions}

A number of limitations of the present study need to be acknowledged, including no functional analysis of MTHFR and CBS enzymes, neither measurements of folate, cobalamin, and even Hcy, and the small sample size in some subgroups evaluated. Nevertheless, this work was an outstanding hypothesis-generating study, suggesting that MTHFR (677C > T) and CBS (844ins68) polymorphisms involvement in SCA pathophysiology is likely to be far more complex than it was explored to date. Briefly, we provided evidence that: i) the polymorphisms investigated did not affect HC treatment, and apparently, they did not present any interaction effect on SCA pathophysiology; ii) $H B B * S$ and MTHFR 677T co-inheritance showed a detrimental effect on antioxidant capacity of people with SCA; iii) $H B B * S$ and $C B S$ (844ins68) coinheritance had a dual impact on pathophysiological processes in SCA patients.

\section{Conflict of interest}

The authors declare no competing financial or other relationship with any people or organization interests.

\section{Acknowledgments}

This work has the financial support of the Brazilian foundations: "Conselho Nacional de Desenvolvimento Científico e Tecnológico CNPq" (grant 140911/2011-1), "Fundação de Amparo à Pesquisa do Estado de São Paulo - FAPESP-CEPID-Redoxoma (2013/07937-8)" and "Coordenação de Aperfeiçoamento de Pessoal de Nível Superior CAPES". E.A. Almeida is a fellowship of productivity of CNPq.

\section{References}

[1] D. Weatherall, K. Hofman, G. Rodgers, J. Ruffin, S. Hrynkow, A case for developing North-South partnerships for research in sickle cell disease, Blood 105 (3) (2005) 921-923.

[2] M.H. Steinberg, P. Sebastiani, Genetic modifiers of sickle cell disease, Am. J. Hematol. 87 (8) (2012) 795-803.

[3] M.H. Steinberg, Predicting clinical severity in sickle cell anaemia, Br. J. Haematol. 129 (4) (2005) 465-481.

[4] M.H. Steinberg, A.H. Adewoye, Modifier genes and sickle cell anemia, Curr. Opin. Hematol. 13 (3) (2006) 131-136.

[5] K.Y. Fertrin, F.F. Costa, Genomic polymorphisms in sickle cell disease: implications for clinical diversity and treatment, Expert Rev. Hematol. 3 (4) (2010) 443-458.

[6] D.G. Silva, E. Belini Junior, E.A. de Almeida, C.R. Bonini-Domingos, Oxidative stress in sickle cell disease: an overview of erythrocyte redox metabolism and current antioxidant therapeutic strategies, Free Radic. Biol. Med. 65 (2013) 1101-1109.

[7] M. Reid, A. Badaloo, T. Forrester, F. Jahoor, In vivo rates of erythrocyte glutathione synthesis in adults with sickle cell disease, Am. J. Physiol. Endocrinol. Metab. 291 (1) (2006) E73-E79.

[8] M.A. Chaves, M.S. Leonart, A.J. do Nascimento, Oxidative process in erythrocytes of individuals with hemoglobin S, Hematology 13 (3) (2008) 187-192.

[9] S.C. Lu, Glutathione synthesis, Biochim. Biophys. Acta 1830 (5) (2013) 3143-3153.

[10] C.R. Morris, J.H. Suh, W. Hagar, S. Larkin, D.A. Bland, M.H. Steinberg, E.P. Vichinsky, M. Shigenaga, B. Ames, F.A. Kuypers, E.S. Klings, Erythrocyte glutamine depletion, altered redox environment, and pulmonary hypertension in sickle cell disease, Blood 111 (1) (2008) 402-410.

[11] V.L. Tatum, C.K. Chow, Antioxidant status and susceptibility of sickle erythrocytes to oxidative and osmotic stress, Free Radic. Res. 25 (2) (1996) 133-139.

[12] R. van Zwieten, A.J. Verhoeven, D. Roos, Inborn defects in the antioxidant systems of human red blood cells, Free Radic. Biol. Med. 67 (2014) 377-386.

[13] J.D. Finkelstein, Methionine metabolism in mammals, J. Nutr. Biochem. 1 (5) (1990) 228-237. 
[14] J. Selhub, Homocysteine metabolism, Annu. Rev. Nutr. 19 (1999) 217-246.

[15] L.J. Hoffer, Homocysteine remethylation and trans-sulfuration, Metab.: Clin. Exp. 53 (11) (2004) 1480-1483.

[16] P.R. Mandaviya, L. Stolk, S.G. Heil, Homocysteine and DNA methylation: a review of animal and human literature, Mol. Genet. Metab. 113 (4) (2014) 243-252.

[17] F.H. Nazki, A.S. Sameer, B.A. Ganaie, Folate: metabolism, genes, polymorphisms and the associated diseases, Gene 533 (1) (2014) 11-20.

[18] P. Frosst, H.J. Blom, R. Milos, P. Goyette, C.A. Sheppard, R.G. Matthews, G.J. Boers, M. den Heijer, L.A. Kluijtmans, L.P. van den Heuvel, et al., A candidate genetic risk factor for vascular disease: a common mutation in methylenetetrahydrofolate reductase, Nat. Genet. 10 (1) (1995) 111-113.

[19] G. Sebastio, M.P. Sperandeo, M. Panico, R. de Franchis, J.P. Kraus, G. Andria, The molecular basis of homocystinuria due to cystathionine beta-synthase deficiency in Italian families, and report of four novel mutations, Am. J. Hum. Genet. 56 (6) (1995) 1324-1333.

[20] P.F. Jacques, A.G. Bostom, R.R. Williams, R.C. Ellison, J.H. Eckfeldt, I.H. Rosenberg, J. Selhub, R. Rozen, Relation between folate status, a common mutation in methylenetetrahydrofolate reductase, and plasma homocysteine concentrations, Circulation 93 (1) (1996) 7-9.

[21] E. Trabetti, Homocysteine, MTHFR gene polymorphisms, and cardio-cerebrovascular risk, J. Appl. Genet. 49 (3) (2008) 267-282.

[22] F. Moreira Neto, D.M. Lourenco, M.A. Noguti, V.M. Morelli, I.C. Gil, A.C. Beltrao, M.S. Figueiredo, The clinical impact of MTHFR polymorphism on the vascular complications of sickle cell disease, Braz. J. Med. Biol. Res. 39 (10) (2006) 1291-1295.

[23] M. Alves Jacob, C. da Cunha, Bastos, C. Regina Bonini-Domingos, The 844ins68 cystathionine beta-synthase and C677T MTHFR gene polymorphism and the vasoocclusive event risk in sickle cell disease, Arch. Med. Sci. 7 (1) (2011) 97-101.

[24] S.S. Nishank, M.P. Singh, R. Yadav, Clinical impact of factor V Leiden, prothrombin G20210A, and MTHFR C677T mutations among sickle cell disease patients of Central India, Eur. J. Haematol. 91 (5) (2013) 462-466.

[25] M.Y. Tsai, M. Bignell, K. Schwichtenberg, N.Q. Hanson, High prevalence of a mutation in the cystathionine beta-synthase gene, Am. J. Hum. Genet. 59 (6) (1996) 1262-1267.

[26] M.Y. Tsai, F. Yang, M. Bignell, O. Aras, N.Q. Hanson, Relation between plasma homocysteine concentration, the 844ins68 variant of the cystathionine betasynthase gene, and pyridoxal-5'-phosphate concentration, Mol. Genet. Metab. 67 (4) (1999) 352-356.

[27] A. Dragani, A. Falco, F. Santilli, S. Basili, G. Rolandi, L. Cerasa, S. Lattanzio, G. Ciabattoni, C. Patrono, G. Davi, Oxidative stress and platelet activation in subjects with moderate hyperhomocysteinaemia due to MTHFR 677 C- > T polymorphism, Thromb. Haemost. 108 (3) (2012) 533-542.

[28] Z. Rahimi, S. Malek-Khosravi, Z. Rahimi, F. Jalilvand, A. Parsian, MTHFR C677T and eNOS G894T variants in preeclamptic women: contribution to lipid peroxidation and oxidative stress, Clin. Biochem. 46 (1-2) (2013) 143-147.

[29] E. Richard, L.R. Desviat, M. Ugarte, B. Perez, Oxidative stress and apoptosis in homocystinuria patients with genetic remethylation defects, J. Cell. Biochem. 114 (1) (2013) 183-191.

[30] A.J. Marengo-Rowe, Rapid electrophoresis and quantitation of haemoglobins on cellulose acetate, J. Clin. Pathol. 18 (6) (1965) 790-792.

[31] F. Vella, Acid-agar gel electrophoresis of human hemoglobins, Am. J. Clin. Pathol. 49 (3) (1968) 440-442.

[32] J. Sambrook, E.F. Fritsch, T. Maniatis, Molecular Cloning: A Laboratory Manual, Cold Spring Harbor Laboratory Press, Cold Spring Harbor, New York, 1989.

[33] R.K. Saiki, S. Scharf, F. Faloona, K.B. Mullis, G.T. Horn, H.A. Erlich, N. Arnheim, Enzymatic amplification of beta-globin genomic sequences and restriction site analysis for diagnosis of sickle cell anemia, Science 230 (4732) (1985) 1350-1354.

[34] M. Sutton, E.E. Bouhassira, R.L. Nagel, Polymerase chain reaction amplification applied to the determination of beta-like globin gene cluster haplotypes, Am. J. Hematol. 32 (1) (1989) 66-69.

[35] H.J. Forman, O. Augusto, R. Brigelius-Flohe, P.A. Dennery, B. Kalyanaraman, H. Ischiropoulos, G.E. Mann, R. Radi, L.J. Roberts 2ndJ. Vina, K.J. Davies, Even free radicals should follow some rules: a guide to free radical research terminology and methodology, Free Radic. Biol. Med. 78 (2015) 233-235.

[36] D.G.H. Silva, O. Júnior-Ricci, E.A. Almeida, C.R. Bonini-Domingos, Potential utility of melatonin as an antioxidant therapy in the management of sickle cell anemia, J. Pineal Res. 58 (2015) 178-188.

[37] E.A. de Almeida, A. Marques Sde, C.F. Klitzke, A.C. Bainy, M.H. de Medeiros, P. Di Mascio, A.P. Loureiro, DNA damage in digestive gland and mantle tissue of the mussel Perna perna, Comp. Biochem. Physiol. Toxicol. Pharmacol. 135c (3) (2003) 295-303.

[38] E.A. de Almeida, S. Miyamoto, A.C. Bainy, M.H. de Medeiros, P. Di Mascio, Protective effect of phospholipid hydroperoxide glutathione peroxidase (PHGPx) against lipid peroxidation in mussels Perna perna exposed to different metals, Mar. Pollut. Bull. 49 (5-6) (2004) 386-392.

[39] E. Beutler, Red Cell Metabolism, A Manual of Biochemical Methods, Grune \& Stratton, New York, 1975.

[40] J.H. Keen, W.H. Habig, W.B. Jakoby, Mechanism for the several activities of the glutathione S-transferases, J. Biol. Chem. 251 (20) (1976) 6183-6188.

[41] H. Sies, O.R. Koch, E. Martino, A. Boveris, Increased biliary glutathione disulfide release in chronically ethanol-treated rats, FEBS Lett. 103 (2) (1979) 287-290.

[42] E. Beutler, Effect of flavin compounds on glutathione reductase activity: in vivo and in vitro studies, J. Clin. Investig. 48 (10) (1969) 1957-1966.

[43] A. Rodriguez-Ariza, F. Toribio, J. Lopez-Barea, Rapid determination of glutathione status in fish liver using high-performance liquid chromatography and electrochemical detection, J. Chromatogr. B Biomed. Appl. 656 (2) (1994) 311-318.
[44] G.P. Quinn, M.J. Keough, Experimental Design and Data Analysis for Biologists, Cambridge University Press, New York, 2002.

[45] J.H. McDonald, Handbook of Biolological Statistics, 3rd ed, Sparky House Publishing, Baltimore, Maryland, 2014.

[46] A. Inati, A. Taher, W. Bou Alawi, S. Koussa, H. Kaspar, H. Shbaklo, P.A. Zalloua, Beta-globin gene cluster haplotypes and HbF levels are not the only modulators of sickle cell disease in Lebanon, Eur. J. Haematol. 70 (2) (2003) 79-83.

[47] R.L. Nagel, Severity, pathobiology, epistatic effects, and genetic markers in sickle cell anemia, Semin. Hematol. 28 (3) (1991) 180-201.

[48] R.F. Franco, J. Elion, J. Lavinha, R. Krishnamoorthy, M.H. Tavella, M.A. Zago, Heterogeneous ethnic distribution of the 844ins68 in the cystathionine betasynthase gene, Hum. Hered. 48 (6) (1998) 338-342.

[49] S.C. Liew, E.D. Gupta, Methylenetetrahydrofolate reductase (MTHFR) C677T polymorphism: epidemiology, metabolism and the associated diseases, Eur. J. Med. Genet. 58 (1) (2015) 1-10.

[50] P. Durand, M. Prost, N. Loreau, S. Lussier-Cacan, D. Blache, Impaired homocysteine metabolism and atherothrombotic disease, Lab. Investig. J. Tech. Methods Pathol. 81 (5) (2001) 645-672.

[51] F.D. Couto, W.V. Boas, I. Lyra, Â. Zanette, M.F. Dupuit, M.N.T. Almeida, M.G. Reis, M. Souza Gonçalves, A C677T methylenetetrahydrofolate reductase (MTHFR) polymorphism and G20210A mutation in the prothrombin gene of sickle cell anemia patients from Northeast Brazil, Hemoglobin 28 (3) (2004) 237-241.

[52] R.E. Ware, B. Aygun, Advances in the use of hydroxyurea, Hematology (2009) 62-69.

[53] R.E. Ware, How I use hydroxyurea to treat young patients with sickle cell anemia, Blood 115 (26) (2010) 5300-5311.

[54] R.E. Ware, Hydroxycarbamide: clinical aspects, Comptes Rendus Biol. 336 (3) (2013) 177-182.

[55] D.L. Jain, M. Apte, R. Colah, V. Sarathi, S. Desai, A. Gokhale, A. Bhandarwar, H.L. Jain, K. Ghosh, Efficacy of fixed low dose hydroxyurea in Indian children with sickle cell anemia: a single centre experience, Indian Pediatr. 50 (10) (2013) 929-933.

[56] C.L.C. Lobo, A.M.M. Queiroz, The mean corpuscular volume and hydroxyurea in Brazilian patients with sickle cell anemia: a surrogate marker of compliance, J. Blood Disord. Transfus. 04 (05) (2013).

[57] S. Charache, Mechanism of action of hydroxyurea in the management of sickle cell anemia in adults, Semin. Hematol. 34 (3 Suppl 3) (1997) S15-S21.

[58] A. Agil, S.M. Sadrzadeh, Hydroxy-urea protects erythrocytes against oxidative damage, Redox Rep.: Commun. Free Radic. Res. 5 (1) (2000) 29-34.

[59] D.G. Silva, E. Belini Junior, S. Torres Lde, O. Ricci Junior, C. Lobo Cde, C.R. BoniniDomingos, E.A. de Almeida, Relationship between oxidative stress, glutathione Stransferase polymorphisms and hydroxyurea treatment in sickle cell anemia, Blood Cells Mol. Dis. 47 (1) (2011) 23-28.

[60] G.P. Rodgers, G.J. Dover, C.T. Noguchi, A.N. Schechter, A.W. Nienhuis, Hematologic responses of patients with sickle cell disease to treatment with hydroxyurea, N. Engl. J. Med. 322 (15) (1990) 1037-1045.

[61] A. Gravia, V. Chondrou, A. Sgourou, I. Papantoni, J. Borg, T. Katsila, A. Papachatzopoulou, G.P. Patrinos, Individualizing fetal hemoglobin augmenting therapy for beta-type hemoglobinopathies patients, Pharmacogenomics 15 (10) (2014) 1355-1364.

[62] P. Goyette, J.S. Sumner, R. Milos, A.M. Duncan, D.S. Rosenblatt, R.G. Matthews, R. Rozen, Human methylenetetrahydrofolate reductase: isolation of cDNA mapping and mutation identification, Nat. Genet. 7 (4) (1994) 551.

[63] P.J. Bagley, J. Selhub, A common mutation in the methylenetetrahydrofolate reductase gene is associated with an accumulation of formylated tetrahydrofolates in red blood cells, Proc. Natl. Acad. Sci. USA 95 (22) (1998) 13217-13220.

[64] A.K. al-Momen, Diminished vitamin B12 levels in patients with severe sickle cell disease, J. Intern. Med. 237 (6) (1995) 551-555.

[65] P. Kamineni, S. Chirla, K. Dinh, S. Hasan, E. Nidhiry, J. Kwagyan, T. Naab, F. Lombardo, O. Castro, F. Dawkins, Low cobalamin levels in African Americans with and without sickle cell disease, J. Natl. Med. Assoc. 98 (3) (2006) 352-356.

[66] O.I. Ajayi, S. Bwayo-Weaver, S. Chirla, M. Serlemitsos-Day, M. Daniel, M. Nouraie, K. Edwards, O. Castro, F. Lombardo, V.R. Gordeuk, Cobalamin status in sickle cell disease, Int. J. Lab. Hematol. 35 (1) (2013) 31-37.

[67] M.J. Koury, P. Ponka, New insights into erythropoiesis: the roles of folate, vitamin B12, and iron, Annu. Rev. Nutr. 24 (2004) 105-131.

[68] S.K. Moestrup, New insights into carrier binding and epithelial uptake of the erythropoietic nutrients cobalamin and folate, Curr. Opin. Hematol. 13 (3) (2006) $119-123$.

[69] S.V. Vijaya Lakshmi, S.M. Naushad, D. Seshagiri Rao, V.K. Kutala, Oxidative stress is associated with genetic polymorphisms in one-carbon metabolism in coronary artery disease, Cell Biochem. Biophys. 67 (2) (2013) 353-361.

[70] T.V. Bagnyukova, C.L. Powell, O. Pavliv, V.P. Tryndyak, I.P. Pogribny, Induction of oxidative stress and DNA damage in rat brain by a folate/methyl-deficient diet, Brain Res. 1237 (2008) 44-51.

[71] L.B. Bailey, J.F. Gregory 3rd, Polymorphisms of methylenetetrahydrofolate reductase and other enzymes: metabolic significance, risks and impact on folate requirement, J. Nutr. 129 (5) (1999) 919-922.

[72] M. Yakub, N. Moti, S. Parveen, B. Chaudhry, I. Azam, M.P. Iqbal, Polymorphisms in MTHFR, MS and CBS genes and homocysteine levels in a Pakistani population, PloS One 7 (3) (2012) e33222.

[73] A.F. Perna, D. Ingrosso, N.G. De Santo, Homocysteine and oxidative stress, Amino Acids 25 (3-4) (2003) 409-417.

[74] J.M. Koh, Y.S. Lee, Y.S. Kim, D.J. Kim, H.H. Kim, J.Y. Park, K.U. Lee, G.S. Kim, Homocysteine enhances bone resorption by stimulation of osteoclast formation and activity through increased intracellular ROS generation, J. Bone Miner. Res. 21 (7) 
(2006) 1003-1011.

[75] C.S. Vanzin, G.B. Biancini, A. Sitta, C.A. Wayhs, I.N. Pereira, F. Rockenbach, S.C. Garcia, A.T. Wyse, I.V. Schwartz, M. Wajner, C.R. Vargas, Experimental evidence of oxidative stress in plasma of homocystinuric patients: a possible role for homocysteine, Mol. Genet. Metab. 104 (1-2) (2011) 112-117.

[76] C. Marinho, I. Alho, D. Arduino, L.M. Falcao, J. Bras-Nogueira, M. Bicho, GST M1/ T1 and MTHFR polymorphisms as risk factors for hypertension, Biochem. Biophys. Res. Commun. 353 (2) (2007) 344-350.

[77] D. Zhang, X. Jiang, P. Fang, Y. Yan, J. Song, S. Gupta, A.I. Schafer, W. Durante, W.D. Kruger, X. Yang, H. Wang, Hyperhomocysteinemia promotes inflammatory monocyte generation and accelerates atherosclerosis in transgenic cystathionine beta-synthase-deficient mice, Circulation 120 (19) (2009) 1893-1902.

[78] E. Vichinsky, New therapies in sickle cell disease, Lancet 360 (9333) (2002) 629-631.

[79] C. Koh, T. Turner, X. Zhao, C.P. Minniti, J.J. Feld, J. Simpson, M. Demino, A.K. Conrey, M.J. Jackson, C. Seamon, D.E. Kleiner, G.J. Kato, T. Heller, Liver stiffness increases acutely during sickle cell vaso-occlusive crisis, Am. J. Hematol.
88 (11) (2013) E250-E254.

[80] J. Koskinas, E.K. Manesis, G.H. Zacharakis, N. Galiatsatos, N. Sevastos, A.J. Archimandritis, Liver involvement in acute vaso-occlusive crisis of sickle cell disease: prevalence and predisposing factors, Scand. J. Gastroenterol. 42 (4) (2007) 499-507.

[81] S.K. Ballas, Lactate dehydrogenase and hemolysis in sickle cell disease, Blood 121 (1) (2013) 243-244.

[82] R.P. Hebbel, W.T. Morgan, J.W. Eaton, B.E. Hedlund, Accelerated autoxidation and heme loss due to instability of sickle hemoglobin, Proc. Natl. Acad. Sci. USA 85 (1) (1988) 237-241.

[83] M.J. Hitchler, F.E. Domann, An epigenetic perspective on the free radical theory of development, Free Radic. Biol. Med. 43 (7) (2007) 1023-1036.

[84] M.C. Reed, R.L. Thomas, J. Pavisic, S.J. James, C.M. Ulrich, H.F. Nijhout, A mathematical model of glutathione metabolism, Theor. Biol. Med. Model. 5 (2008) 8.

[85] H.F. Nijhout, M.C. Reed, C.M. Ulrich, Mathematical models of folate-mediated onecarbon metabolism, Vitam. Horm. 79 (2008) 45-82. 